Tohoku J. Exp. Med., 2021, 255, 1-8

Review

\title{
Coagulation, Protease-Activated Receptors, and Diabetic Kidney Disease: Lessons from eNOS-Deficient Mice
}

\author{
Yuji Oe, ${ }^{1}$ Mariko Miyazaki ${ }^{1}$ and Nobuyuki Takahashi ${ }^{2}$ \\ ${ }^{1}$ Division of Nephrology, Endocrinology, and Vascular Medicine, Tohoku University Graduate School of \\ Medicine, Sendai, Miyagi, Japan \\ ${ }^{2}$ Division of Clinical Pharmacology and Therapeutics, Tohoku University Graduate School of Pharmaceutical \\ Sciences \& Faculty of Pharmaceutical Sciences, Sendai, Miyagi, Japan
}

\begin{abstract}
Endothelial nitric oxide synthase (eNOS) dysfunction is known to exacerbate the progression and prognosis of diabetic kidney disease (DKD). One of the mechanisms through which this is achieved is that low eNOS levels are associated with hypercoagulability, which promotes kidney injury. In the extrinsic coagulation cascade, the tissue factor (factor III) and downstream coagulation factors, such as active factor X (FXa), exacerbate inflammation through activation of the protease-activated receptors (PARs). Recently, it has been shown that the lack of or reduced eNOS expression in diabetic mice, as a model of advanced DKD, increases renal tissue factor levels and PAR1 and 2 expression in their kidneys. Furthermore, pharmaceutical inhibition or genetic deletion of coagulation factors or PARs ameliorated inflammation in DKD in mice lacking eNOS. In this review, we summarize the relationship between eNOS, coagulation, and PARs and propose a novel therapeutic option for the management of patients with DKD.
\end{abstract}

Keywords: diabetic glomerulosclerosis; factor Xa; inflammation; tissue factor

Tohoku J. Exp. Med., 2021 September, 255 (1), 1-8.

\section{Introduction}

The number of patients with diabetic kidney disease (DKD) is increasing worldwide (de Boer et al. 2011; Kainz et al. 2015; Ogurtsova et al. 2017). DKD is one of the major causes of mortality in patients with diabetic complications (Afkarian et al. 2013). Furthermore, DKD is progressive and is the main cause of end-stage kidney disease requiring renal replacement therapy (Gregg et al. 2014; Liyanage et al. 2015). In Japan, diabetic nephropathy accounts for more than $39 \%$ of new dialysis patients (Nitta et al. 2020). Therefore, the development of novel therapeutic options is required to manage patients with DKD.

There is increasing interest in the role of the coagulation system in DKD pathogenesis. Hypercoagulability is associated with DKD (Goldberg 2009; Domingueti et al. 2016). An elevated fibrinogen level in blood was shown to be associated with low estimated glomerular filtration rate, high proteinuria, and severe histological injury, and it was a predictor of the progression to end-stage kidney disease (Dalla Vestra et al. 2005; Pan et al. 2018; Zhang et al. 2018). Some studies have shown a correlation between the level of D-dimer, a fibrin degradation product, and renal dysfunction in DKD (Domingueti et al. 2018; Pan et al. 2018). Hypercoagulability in DKD is likely determined by multiple factors. For example, renin-angiotensin-aldosterone system activates tissue factor (TF, factor III) and increases thrombotic events (Dielis et al. 2005). Otherwise, hyperglycemia, dyslipidemia, inflammation, or endothelial dysfunction are involved in the pro-thrombotic state under DKD pathogenesis (Goldberg 2009).

Endothelial dysfunction is present in DKD that progresses to microvascular complications (Goldberg 2009; Nakagawa et al. 2011). Impaired endothelial nitric oxide synthase (eNOS) production or reduced eNOS activity (e.g., impaired eNOS phosphorylation) is a hallmark of endothelial dysfunction in DKD (Nakagawa et al. 2011; Cheng et al. 2012). We have shown that a loss of eNOS expression was linked to the elevation in the TF level and the extrinsic coagulation system activity ( $\mathrm{Li}$ et al. 2010; Wang et al. 2011a), which is closely associated with thrombotic events in patients with chronic kidney diseases (Kolachalama et al. 2018).

In addition to the elevated risk of thrombotic events,

Received May 4, 2021; revised and accepted June 13, 2021. Published online September 11, 2021; doi: 10.1620/tjem.255.1.

Correspondence: Yuji Oe, M.D., Ph.D., Department of Nephrology, Endocrinology, and Vascular Medicine, Tohoku University Graduate

School of Medicine, 1-1 Seiryo-machi, Aoba-ku, Sendai, Miyagi 980-8574, Japan.

e-mail: yuji-oe@med.tohoku.ac.jp

(C)2021 Tohoku University Medical Press. This is an open-access article distributed under the terms of the Creative Commons Attribution-NonCommercial-NoDerivatives 4.0 International License (CC-BY-NC-ND 4.0). Anyone may download, reuse, copy, reprint, or distribute the article without modifications or adaptations for non-profit purposes if they cite the original authors and source properly.

https://creativecommons.org/licenses/by-nc-nd/4.0/ 
coagulation proteases, such as active factor FVII (FVIIa), active factor (FXa), and thrombin, which are present in the extrinsic coagulation cascade, mediate tissue injury through a protease-activated receptor (PAR)-dependent mechanism (Madhusudhan et al. 2016; Posma et al. 2019). In this review, we summarize the findings obtained from diabetic mice lacking eNOS and discuss the relationship between the coagulation-PAR pathway, eNOS levels, and DKD pathogenesis.

\section{Tissue Factor/Protease-Activated Receptors Pathway}

Tissue factor (TF), known as factor III, is a $47 \mathrm{kDa}$ transmembrane protein that interacts with factor VII (FVII) (Grover and Mackman 2018). The TF/FVIIa complex is an activator of the extrinsic coagulation cascade and catalyzes the activation of FX and FIX. FXa and activated co-factor $\mathrm{V}$ (FVa) form a prothrombotic complex that generates thrombin. Finally, thrombin converts fibrinogen to fibrin, resulting in the formation of thrombi (Grover and Mackman 2018). TF is expressed in both vascular smooth muscle cells and adventitial fibroblasts. Under inflammatory conditions, its expression is induced in endothelial cells or circulating cells such as monocytes (Østerud and Bjørklid 2006).

Protease-activated receptors (PARs) are members of the G-protein-coupled receptor superfamily, comprising four PAR proteins (PAR1-4). PARs undergo cleavage by proteases at the N-terminal end and are activated upon binding to a new $\mathrm{N}$-terminus containing a tethered ligand. The four members of PARs (PAR1-4) are activated by specific coagulation proteases: the TF and FVIIa complex activates PAR2, factor Xa activates both PAR1 and PAR2, and thrombin activates PAR1, PAR3, and PAR4 (Camerer et al. 2000; Coughlin 2005; Rothmeier and Ruf 2012; Zhao et al. 2014). The relationship between TF, coagulation proteases, and PARs is shown in Fig. 1.
PARs are known to be widely expressed in renal cells and are involved in the pathophysiology of kidney injury. Both PAR1 and PAR2 are expressed in glomerular endothelial cells, mesangial cells, and kidney tubular cells derived from human or mouse; PAR2, PAR3, and PAR4 are expressed in human podocytes; PAR1, PAR3, and PAR4 are expressed in murine podocytes (Tanaka et al. 2005; Vesey et al. 2005; Madhusudhan et al. 2012; Dong et al. 2015; Madhusudhan et al. 2016).

Although the harmful or protective effects of PARs in kidney injury have been demonstrated, accumulating data suggest that PARs exacerbate inflammation by stimulating the production of cytokines and chemokines (Rothmeier and Ruf 2012; Isermann 2017; Posma et al. 2019). Consistent with this finding, PAR1 and PAR2 agonists promote the expression of inflammatory mediators, such as monocyte chemotactic protein 1 (MCP1) and plasminogen activator inhibitor-1 (PAI-1), and pro-fibrotic molecules in endothelial, mesangial, and kidney tubular cells (Vesey et al. 2005; Vesey et al. 2013; Ellinghaus et al. 2016; Waasdorp et al. 2016; Oe et al. 2019). In in vivo studies, the lack of PAR1 or the presence of PAR1 inhibitors reduced inflammation in models of crescentic glomerulonephritis or obstructive kidney injury (Cunningham et al. 2000; Waasdorp et al. 2019; Lok et al. 2020). Similarly, the therapeutic effects of PAR2 inhibition in kidney injuries were accompanied by a reduction in inflammation in the kidneys (Hayashi et al. 2016; Du et al. 2017; Han et al. 2019; Watanabe et al. 2019).

\section{Endothelial Nitoric Oxide Synthase Polymorphisms in DKD}

Endothelial nitoric oxide synthase (eNOS) is one of the three NOS isoforms, and it contributes to the production of $\mathrm{NO}$ in the vascular endothelium (Walford and Loscalzo 2003). NO produced by eNOS in the vascular endothelium

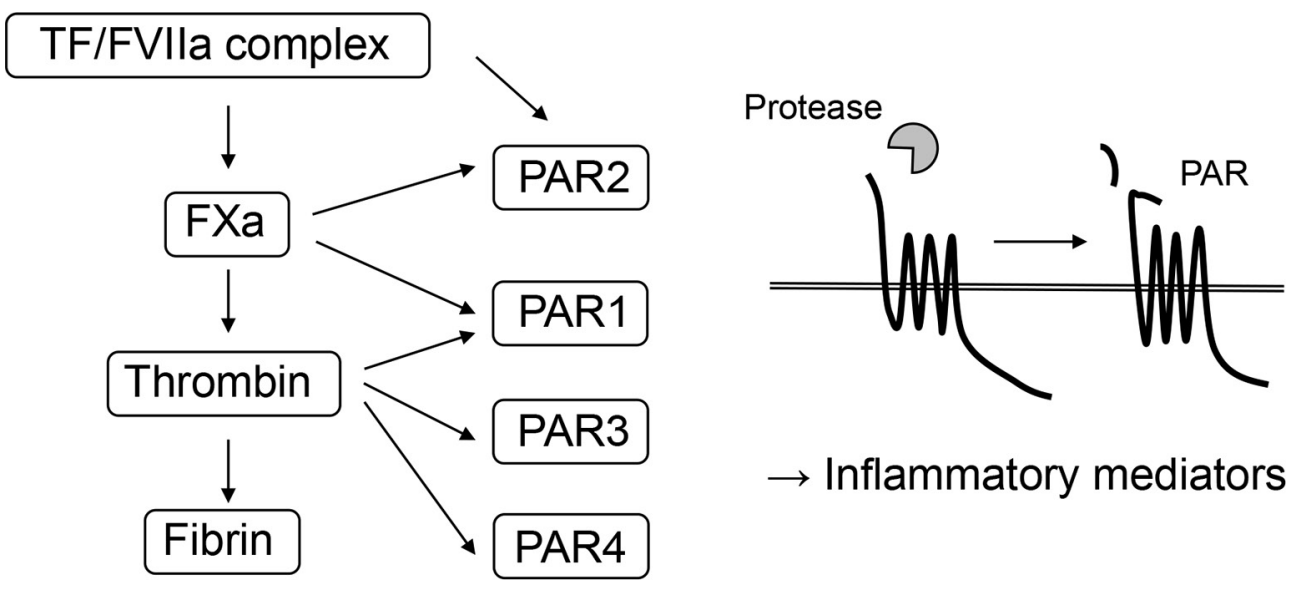

Fig. 1. Relationship between coagulation factors and protease-activated receptors (PARs).

In the extrinsic coagulation cascade, the tissue factor (TF) and active FVII (FVIIa) complex activates protease-activated receptor 2 (PAR2), active FX (FXa) activates both PAR1 and PAR2, and thrombin targets PAR1, PAR3, and PAR4. Cleavage of the $\mathrm{N}$-terminal sequence of PARs by coagulation proteases reveals a new $\mathrm{N}$-terminal sequence that acts as a tethered ligand and promotes inflammation. 
plays a crucial role in regulating vascular relaxation, antiinflammation, and prevention of thrombus formation (Walford and Loscalzo 2003). Impaired eNOS expression is associated with the development of DKD. Recently conducted meta-analyses on humans have revealed that G894T (rs1799983), C-786T (rs2070744), and intron 4b/4a (rs869109213) in eNOS (NOS3) genes are closely associated with the development of DKD (Dellamea et al. 2014; Zhang et al. 2015; Dong et al. 2018). Of these variants, the role of the G894T (Glu298Asp) polymorphism in eNOS function has been well characterized. The reduced production of NO or nitrite accumulation was indicated in transfected CHO cells with 298Asp compared to those with 298Glu (Noiri et al. 2002). Collectively, these results indicate that the reduced production of NO by eNOS dysfunction is important for the progression of DKD in humans.

\section{Diabetic Mice Lacking eNOS as a Model of Human Diabetic Nephropathy}

Establishment of reliable preclinical models resembling human DKD is essential for the study of novel therapeutic options. Based on the evidence showing an association between eNOS polymorphism and DKD, a number of studies have demonstrated that eNOS knock-out models of type I and type II DM are some of the successful models mimicking human DKD (Brosius et al. 2009; Azushima et al. 2018). It was demonstrated that streptozotocin-induced diabetic mice lacking eNOS develop severe albuminuria, mesangial expansion, thickening of the glomerular basement membrane, and arteriolar hyalinosis, resembling human DKD (Nakagawa et al. 2007). Similarly, type II diabetic mice $(\mathrm{db} / \mathrm{db})$ lacking eNOS showed severe glomerulosclerosis and albuminuria (Zhao et al. 2006).

\section{Elevated TF in Diabetic Mice Lacking eNOS}

NO inhibits thrombus formation and platelet aggregation (Walford and Loscalzo 2003). Because glomerular thrombus formation was observed in diabetic mice lacking eNOS (Nakagawa et al. 2007), impaired eNOS expression is likely associated with the increase in TF-dependent coagulation. The association between eNOS and TF in DKD has been addressed in our previous reports (Li et al. 2010; Wang et al. 2011a; Oe et al. 2016) (Fig. 2).

Reduced or a lack of eNOS expression increases renal TF activity in diabetic Akita mice

We characterized TF expression in diabetic Akita (Ins $2^{\text {Akita/+ }}$ ) mice, a model of type I DM, with various expression levels of eNOS $\left(e \mathrm{NOS}^{+/+}, e \mathrm{NOS}^{+/}\right.$, and $\left.e \mathrm{NOS}^{+/}\right)$ (Wang et al. 2011a). We found that the severity of DKD was associated with reduced eNOS expression. Urinary albumin excretion, glomerulosclerosis, and reduction in glomerular filtration rate were exacerbated in the following order: $\mathrm{eNOS}^{+/+}$; Ins $2^{\text {Akita/+ }}<\mathrm{eNOS}^{+/-}$; Ins $2^{\text {Akita/+ }}<\mathrm{eNOS}^{+-}$; Ins $2^{\text {Akita/ }+}$. Interestingly, kidney TF expression and activity were increased in $\mathrm{eNOS}^{+/-}$; Ins $2^{\text {Akita/+ }}$ and $e \mathrm{NOS}^{-/-}$; Ins $2^{\text {Akita/+ }}$ mice compared with those in $\mathrm{eNOS}^{+/+}$; Ins $2^{\text {Akita/+ }}$ mice. Glomerular fibrin deposition was also remarkable in $e N O S^{+/-} ;$Ins $2^{\text {Akita/+ }}$ and $e N O S^{-/-}$; Ins $2^{\text {Akital+ }}$ mice. Furthermore, renal $T f$ mRNA expression was correlated with disease severity, urinary albumin excretion, and renal inflammatory cytokine expression.

High-fat diet and lack of eNOS synergistically increase TF in diabetic mice

Many studies have demonstrated a connection between obesity and thrombosis (Samad and Ruf 2013). For exam-

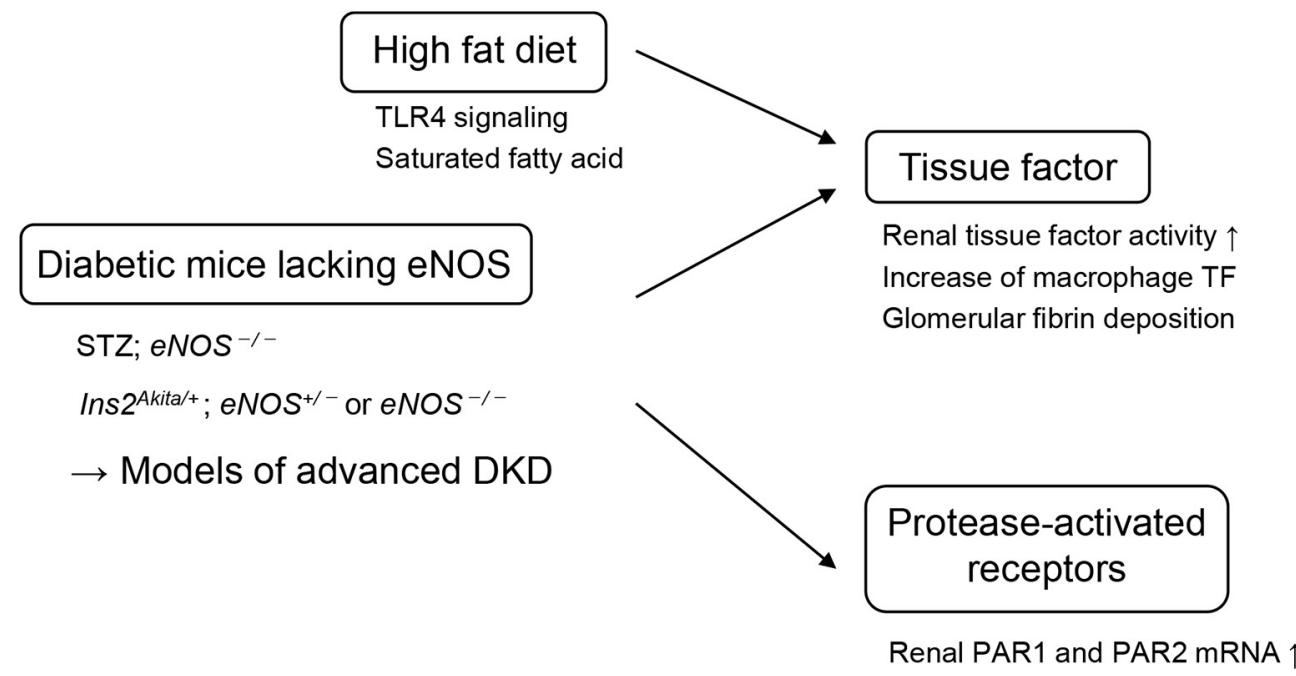

Fig. 2. Lack of eNOS expression is associated with an increase in tissue factor (TF) and protease-activated receptor (PAR) expression in diabetic kidneys.

Lack or reduced expression of eNOS in diabetic mice, models of advanced diabetic kidney disease (DKD), increases renal tissue factor (TF) activity. Furthermore, a high-fat diet synergistically increases TF levels. Similarly, the renal expression levels of Par1 and Par2 mRNA were increased in diabetic mice lacking eNOS. 
ple, upregulation of the TLR4-NF-kB pathway under metabolic disease conditions increases TF levels (Lv et al. 2009; Owens et al. 2012; Rogero and Calder 2018). Furthermore, saturated fatty acid palmitate induces histone $\mathrm{H} 3$ release via ROS and JNK pathway-dependent mechanisms and extracellular histones, which increase TF expression in monocytes (Shrestha et al. 2013). Focusing on the relationship between coagulation, eNOS, and dyslipidemia, our previous study has demonstrated the combined effects of eNOS deficiency and a high-fat diet on TF expression ( $\mathrm{Li}$ et al. 2010). In the study, eNOS-null mice were treated with low-dose STZ to develop DM and were fed a high-fat diet. The lack of eNOS expression increased urinary albumin excretion and histological injuries, which were further exacerbated by a high-fat diet. The expression and activity of TF were increased in mouse kidneys because of a lack of eNOS expression and a high-fat diet in a synergistic manner. Interestingly, an increase in the level of immunoreactive TF was demonstrated by colocalization experiments with a glomerular monocyte/macrophage marker.

\section{Neutralizing Antibodies against TF Ameliorate Inflammation in Diabetic Kidneys in eNOS-Knockout Mice}

An increase in TF-dependent coagulation is associated with increased inflammation (Witkowski et al. 2016). Inhibition of the TF-dependent coagulation system ameliorated inflammatory diseases, such as LPS-induced sepsis (Pawlinski et al. 2010). To elucidate the causal link between inflammation and TF in DKD, we examined the short-term effect of neutralizing antibodies against TF on inflammation of diabetic kidneys in eNOS-deficient mice (Li et al. 2010). The results showed that administration of anti-TF antibodies markedly reduced the renal expression levels of inflammation- and fibrosis-related genes such as
Tnfa, Ccl2, Tgfb, and Col4 mRNA in mouse kidneys four days after TF neutralization.

\section{Coagulation FXa Inhibitor Ameliorates Kidney Injury in Diabetic Mice Lacking eNOS}

Coagulation FXa, located downstream of TF/VIIa, also contributes to inflammation through PAR-dependent pathway. Its role in DKD has been demonstrated in several animal models. Sumi et al. (2011) demonstrated that fondaparinux, an FXa inhibitor, reduced urinary protein levels, glomerular hypertrophy, and fibrin deposition in $\mathrm{db} /$ $\mathrm{db}$ mice. The therapeutic effect of FXa inhibition in DKD mice lacking eNOS was demonstrated by our group (Oe et al. 2016). Edoxaban (50 mg/kg/day), an oral $\mathrm{FXa}$ inhibitor, was administered to $\mathrm{eNOS}^{-/}$; Ins $2^{\text {Akita/+ }}$ mice for three months, and the results showed amelioration of histological injury, such as mesangial matrix proliferation. The expression levels of inflammatory genes in the kidneys were reduced by edoxaban (Table 1). FXa activates both PAR1 and PAR2. To elucidate the mechanism of FXa-mediated kidney injury, we demonstrated that the anti-inflammatory effects of FXa inhibitors are similar to those found in $P A R 2^{--}$ mice and $P A R 2^{-/}$mice with FXa inhibitors. These findings suggested that FXa likely caused inflammation through a PAR2-dependent mechanism in DKD. In contrast, edoxaban did not improve glomerular injury in $\mathrm{eNOS}^{+/+} ;$Ins $2^{\text {Akita } /+}$ mice, suggesting that the therapeutic effect of FXa inhibition was associated with eNOS-dependent hypercoagulability in type I diabetic mice.

\section{Other Coagulation Factors in DKD}

Because thrombin targets PAR1, which progresses vascular inflammation (Chen and Dorling 2009), thrombin likely exacerbates DKD. However, the protective or harmful roles of thrombin in DKD pathogenesis have been dem-

Table 1. Effects of tissue factor (TF), coagulation factor Xa (FXa), and protease-activated receptor (PAR) inhibition in diabetic kidney disease (DKD) mice with reduced or lacking eNOS expression.

\begin{tabular}{|c|c|c|c|c|}
\hline Diabetic model & eNOS genotype & Therapeutic intervention & Outcomes & Reference \\
\hline STZ & $e N O S^{-/}$ & Anti-TF antibody & Cytokines/chemokines $\downarrow$ & Li et al. (2010) \\
\hline Ins $2^{\text {Akita/+ }}$ & $e N O S^{-}$ & Edoxaban (FXa inhibitor) & $\begin{array}{l}\text { Mesangial matrix area } \downarrow \\
\text { Cytokines/chemokines } \downarrow\end{array}$ & Oe et al. (2016) \\
\hline Ins $2^{\text {Akita/+ }}$ & $e N O S^{+/}$ & PAR2 knock-out & $\begin{array}{l}\text { Urinary albumin excretion } \downarrow \\
\text { Mesangial matrix area } \downarrow \\
\text { Cytokines/chemokines } \downarrow\end{array}$ & Oe et al. (2016) \\
\hline $\operatorname{Ins} 2^{\text {Akita/+ }}$ & $e N O S^{+/}$ & E5555 (PAR1 antagonist) & $\begin{array}{l}\text { Mesangial matrix area } \downarrow \\
\text { Glomerular collagen IV expression } \downarrow\end{array}$ & Mitsui et al. (2020) \\
\hline Ins $2^{\text {Akita/+ }}$ & $e N O S^{+/-}$ & FSLLRY (PAR2 antagonist peptide) & $\begin{array}{l}\text { Mesangial matrix area } \downarrow \\
\text { Glomerular collagen IV expression } \downarrow\end{array}$ & \\
\hline Ins $2^{\text {Akital+ }}$ & $e N O S^{+/}$ & E5555 + FSLLRY & $\begin{array}{l}\text { Urinary albumin excretion } \downarrow \\
\text { Mesangial matrix area } \downarrow \\
\text { Glomerular collagen IV expression } \downarrow \\
\text { Glomerular macrophage infiltration } \downarrow \\
\text { Cytokines/chemokines } \downarrow\end{array}$ & \\
\hline
\end{tabular}

DKD, diabetic kidney disease; eNOS, endothelial nitric oxide synthase; TF, tissue factor; FXa, coagulation factor Xa; PAR, proteaseactivated receptor; STZ, streptozotocin. 
onstrated; low-dose thrombin (50 pM) prevented, whereas high-dose thrombin (20 nM) aggravated, glucose-induced apoptosis in podocytes (Wang et al. 2011b). The effects of thrombin inhibitors such as dabigatran on diabetic mice lacking eNOS should be elucidated in the future.

Fibrinogen is involved in various inflammatory statuses. Interestingly, partial reduction or the absence of fibrinogen was beneficial to renal ischemia-reperfusion models or obstructive kidney fibrosis (Sörensen et al. 2011; Craciun et al. 2014). Because glomerular fibrin deposition is increased in diabetic mice lacking eNOS (Nakagawa et al. 2007; Li et al. 2010; Wang et al. 2011a), elucidating its role in DKD pathogenesis deserves further research.

\section{Expression of PAR1 and PAR2 in Diabetic Mice Lacking eNOS}

Increased expression of PARs is associated with kidney injury. We and others have demonstrated that the expression levels of Parl and/or Par 2 mRNA were increased in animal models with diabetic nephropathy, adenine-induced kidney injury, obstructive renal fibrosis, and cisplatin-induced kidney injury (Chung et al. 2013; Hayashi et al. 2016; Oe et al. 2016; Watanabe et al. 2019). Furthermore, glomerular PAR2 protein levels were increased in $\mathrm{db} / \mathrm{db}$ mice, a model of type II DM (Sumi et al. 2011). We demonstrated the association between PAR expression and eNOS deficiency in diabetic mice (Oe et al. 2016). The expression level of Parl mRNA was significantly higher in $\mathrm{eNOS}^{-/-}$; Ins $2^{\text {Akita/+ }}$ mice than in $\mathrm{eNOS}^{-/-}$; $\operatorname{Ins} 2^{\text {Akita/+ }}$ and non-DM mice. Similarly, the expression of Par2 was significantly higher in $\mathrm{eNOS}^{-/-}$; Ins $2^{\text {Akita/+ }}$ mice than in non-DM mice. In contrast, Par4 mRNA levels did not differ between the genotypes. A lack of eNOS exacerbates inflammation in DKD (Wang et al. 2011a). Because pro-inflammatory cytokines reportedly increase PARs (Nystedt et al. 1996), elevated inflammation caused by a lack of eNOS likely induces renal Pars expression in DKD. Collectively, the results of our studies suggested that the expression levels of PAR1 and PAR2, similar to the case of $\mathrm{TF}$, were increased in diabetic kidneys when eNOS was lacking (Fig. 2).

\section{PAR2 Deletion Ameliorated Diabetic Kidney Injury in Mice with Reduced eNOS}

We and others have addressed the role of PAR2 in DKD in previous studies. Par2 deletion did not affect glomerular injury in diabetic wild-type Akita mice (Ins $2^{\text {Akita/+ }}$ ) with eNOS (Oe et al. 2016). Furthermore, STZ-induced diabetic mice lacking PAR2 showed reduced albuminuria compared to diabetic wild-type mice, but increased mesangial expansion (Waasdorp et al. 2017). Collectively, these results demonstrate that there are no or mild therapeutic effects of PAR2 inhibition on kidney injury in the early and mild models of DKD. In contrast, we have demonstrated the effects of PAR2 deficiency on DKD in diabetic Akita mice with reduced expression of eNOS $\left(e \mathrm{NOS}^{+/-} ; \operatorname{Ins} 2^{\text {Akita/+ }}\right)$
(Oe et al. 2016). The lack of PAR2 significantly reduced the levels of urinary albumin excretion, mesangial expansion, and thickness of the GBM. The expression levels of pro-inflammatory and fibrosis-related genes, including $T n f a, T g f b$, and Col4, were also reduced in mouse kidneys. These findings suggest that PAR2 is pathogenic not in early, but in the relatively advanced diabetic glomerular injury caused by eNOS deficiency (Table 1).

\section{Dual Blockade of PAR1 and PAR2 in Diabetic Mice with Reduced eNOS}

We have demonstrated that PAR1 and PAR2 cooperatively contribute to DKD pathogenesis (Mitsui et al. 2020). In this study, male type I diabetic Akita mice heterozygous for eNOS (Ins $2^{A k i t a /+}$; eNOS ${ }^{+/}$) were used as a model of DKD. These mice were treated with vehicle, PAR1 antagonist (E5555, $60 \mathrm{mg} / \mathrm{kg} /$ day), PAR2 antagonist (FSLLRY, 3 $\mathrm{mg} / \mathrm{kg} / \mathrm{day})$, or E5555 + FSLLRY for 4 weeks. Administration of the PAR1 or PAR2 antagonist alone attenuated glomerular injury, such as mesangial expansion and collagen IV deposition, compared to administration of vehicle. Synergistic therapeutic effects of both PAR1 and PAR2 inhibition were observed, and the urinary albumin to creatinine ratio was significantly reduced when both PAR1 and PAR2 were blocked with E5555 + FSLLRY compared with the vehicle administration. Furthermore, dual blockade of PAR1 and PAR2 by E5555 + FSLLRY synergistically ameliorated histological injury, including mesangial expansion, glomerular macrophage infiltration, and deposition of type IV collagen. The expression levels of inflammation- and fibrosis-related genes in the kidneys were also reduced (Table 1).

We focused on the pro-inflammatory effects of PAR1 and PAR2 agonists on human endothelial cells (Mitsui et al. 2020). The results showed that stimulation with both PAR1 and PAR2 agonists synergistically increased the expression levels of MCP1 and PAII mRNA. The effect of the PAR1 agonist was blocked by an NF- $\kappa \mathrm{B}$ inhibitor, whereas that of the PAR2 agonist was blocked by NF-kB and MAPK inhibitors. Collectively, PAR1 and PAR2 cooperatively contribute to vascular inflammation and DKD through different signaling pathways (Fig. 3).

\section{Conclusion}

In this review, we focused on the relationship between the coagulation protease-PAR pathway and eNOS deficiency in diabetic mice. Low production of eNOS is linked to hypercoagulability and increased PAR signaling, which are harmful in DKD. These findings may indicate their pathological roles in advanced or later phase of DKD (e.g., with renal failure and/or massive proteinuria). Oral FXa inhibitors are widely used to prevent thrombosis (Patel et al. 2011; Robertson et al. 2015). Their use in the treatment of DKD is a promising option. Furthermore, some PAR1 antagonists, including atopaxar and vorapaxar, can be used in antiplatelet therapy to prevent acute coronary syndrome 


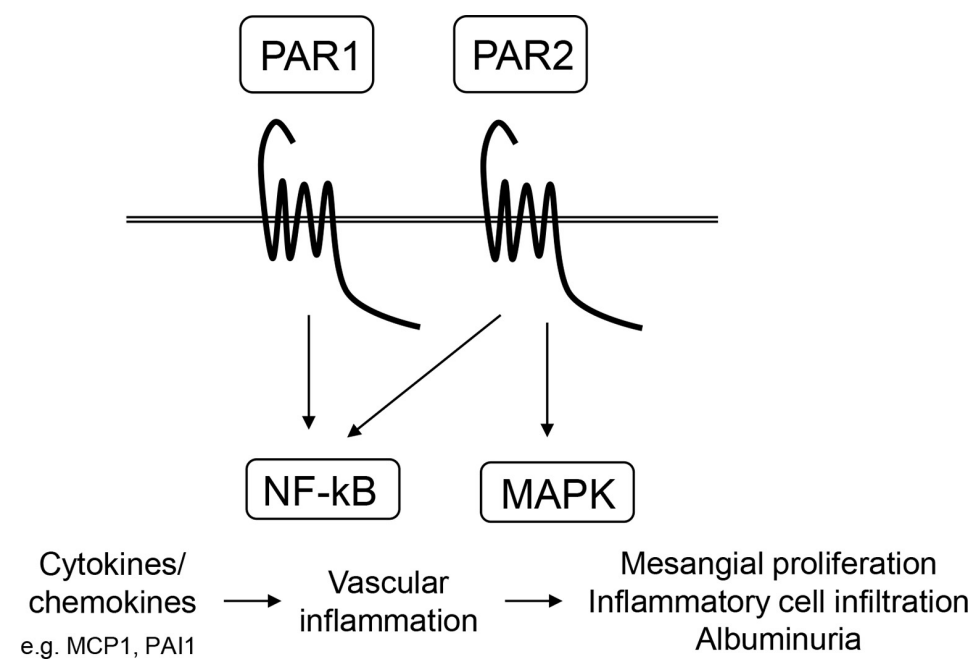

Fig. 3. Distinct roles of PAR1 and PAR2 in vascular inflammation and diabetic kidney disease (DKD). In human endothelial cells, the PAR1 agonist increases chemokine and cytokine expression via the NF- $\kappa$ B signaling pathway, whereas the PAR2 agonist increases them via the NF- $\kappa$ B and MAPK signaling pathways. PAR1 and PAR2 synergistically cause vascular inflammation via distinct pathways in DKD.

(Goto et al. 2010; Tricoci et al. 2012). In addition, there is remarkable progress in the development of PAR2 antagonists (Lim et al. 2013; Cheng et al. 2017; Jiang et al. 2018), and they can be novel therapeutic options to treat patients with DKD.

\section{Acknowledgments}

This study was supported by Gonryo Medical Foundation. We would like to thank Editage (https://www. editage.com) for English language editing.

\section{Conflict of Interest}

The authors declare no conflict of interest.

\section{References}

Afkarian, M., Sachs, M.C., Kestenbaum, B., Hirsch, I.B., Tuttle, K.R., Himmelfarb, J. \& de Boer, I.H. (2013) Kidney disease and increased mortality risk in type 2 diabetes. J. Am. Soc. Nephrol., 24, 302-308.

Azushima, K., Gurley, S.B. \& Coffman, T.M. (2018) Modelling diabetic nephropathy in mice. Nat. Rev. Nephrol., 14, 48-56.

Brosius, F.C., Alpers, C.E., Bottinger, E.P., Breyer, M.D., Coffman, T.M., Gurley, S.B., Harris, R.C., Kakoki, M., Kretzler, M., Leiter, E.H., Levi, M., McIndoe, R.A., Sharma, K., Smithies, O., Susztak, K., et al. (2009) Mouse models of diabetic nephropathy. J. Am. Soc. Nephrol., 20, 2503-2512.

Camerer, E., Huang, W. \& Coughlin, S.R. (2000) Tissue factorand factor X-dependent activation of protease-activated receptor 2 by factor VIIa. Proc. Natl. Acad. Sci. U. S. A., 97, $5255-5260$

Chen, D. \& Dorling, A. (2009) Critical roles for thrombin in acute and chronic inflammation. J. Thromb. Haemost., 7 Suppl 1, 122-126.

Cheng, H., Wang, H., Fan, X., Paueksakon, P. \& Harris, R.C. (2012) Improvement of endothelial nitric oxide synthase activity retards the progression of diabetic nephropathy in $\mathrm{db} /$ db mice. Kidney Int., 82, 1176-1183.

Cheng, R.K.Y., Fiez-Vandal, C., Schlenker, O., Edman, K., Aggeler, B., Brown, D.G., Brown, G.A., Cooke, R.M.,
Dumelin, C.E., Doré, A.S., Geschwindner, S., Grebner, C., Hermansson, N.O., Jazayeri, A., Johansson, P., et al. (2017) Structural insight into allosteric modulation of protease-activated receptor 2. Nature, 545, 112-115.

Chung, H., Ramachandran, R., Hollenberg, M.D. \& Muruve, D.A. (2013) Proteinase-activated receptor-2 transactivation of epidermal growth factor receptor and transforming growth factor- $\beta$ receptor signaling pathways contributes to renal fibrosis. J. Biol. Chem., 288, 37319-37331.

Coughlin, S.R. (2005) Protease-activated receptors in hemostasis, thrombosis and vascular biology. J. Thromb. Haemost., 3, 1800-1814.

Craciun, F.L., Ajay, A.K., Hoffmann, D., Saikumar, J., Fabian, S.L., Bijol, V., Humphreys, B.D. \& Vaidya, V.S. (2014) Pharmacological and genetic depletion of fibrinogen protects from kidney fibrosis. Am. J. Physiol. Renal Physiol., 307, F471484.

Cunningham, M.A., Rondeau, E., Chen, X., Coughlin, S.R., Holdsworth, S.R. \& Tipping, P.G. (2000) Protease-activated receptor 1 mediates thrombin-dependent, cell-mediated renal inflammation in crescentic glomerulonephritis. J. Exp. Med., 191, 455-462.

Dalla Vestra, M., Mussap, M., Gallina, P., Bruseghin, M., Cernigoi, A.M., Saller, A., Plebani, M. \& Fioretto, P. (2005) Acutephase markers of inflammation and glomerular structure in patients with type 2 diabetes. J. Am. Soc. Nephrol., 16 Suppl $1, \mathrm{~S} 78-82$

de Boer, I.H., Rue, T.C., Hall, Y.N., Heagerty, P.J., Weiss, N.S. \& Himmelfarb, J. (2011) Temporal trends in the prevalence of diabetic kidney disease in the United States. JAMA, 305, 2532-2539.

Dellamea, B.S., Pinto, L.C., Leitão, C.B., Santos, K.G. \& Canani, L.H. (2014) Endothelial nitric oxide synthase gene polymorphisms and risk of diabetic nephropathy: a systematic review and meta-analysis. BMC Med. Genet., 15, 9.

Dielis, A.W., Smid, M., Spronk, H.M., Hamulyak, K., Kroon, A.A., ten Cate, H. \& de Leeuw, P.W. (2005) The prothrombotic paradox of hypertension: role of the renin-angiotensin and kallikrein-kinin systems. Hypertension, 46, 1236-1242.

Domingueti, C.P., Dusse, L.M., Carvalho, M., de Sousa, L.P., Gomes, K.B. \& Fernandes, A.P. (2016) Diabetes mellitus: the linkage between oxidative stress, inflammation, hypercoagulability and vascular complications. J. Diabetes Complications, 
30, 738-745.

Domingueti, C.P., Fóscolo, R.B., Dusse, L.M.S., Reis, J.S., Carvalho, M.D.G., Gomes, K.B. \& Fernandes, A.P. (2018) Association of different biomarkers of renal function with D-dimer levels in patients with type 1 diabetes mellitus (renal biomarkers and D-dimer in diabetes). Arch. Endocrinol. Metab., 62, 27-33.

Dong, J., Ping, Y., Wang, Y. \& Zhang, Y. (2018) The roles of endothelial nitric oxide synthase gene polymorphisms in diabetes mellitus and its associated vascular complications: a systematic review and meta-analysis. Endocrine, 62, 412-422.

Dong, W., Wang, H., Shahzad, K., Bock, F., Al-Dabet, M.M., Ranjan, S., Wolter, J., Kohli, S., Hoffmann, J., Dhople, V.M., Zhu, C., Lindquist, J.A., Esmon, C.T., Gröne, E., Gröne, H.J., et al. (2015) Activated protein $C$ ameliorates renal ischemiareperfusion injury by restricting Y-box binding protein-1 ubiquitination. J. Am. Soc. Nephrol., 26, 2789-2799.

Du, C., Zhang, T., Xiao, X., Shi, Y., Duan, H. \& Ren, Y. (2017) Protease-activated receptor-2 promotes kidney tubular epithelial inflammation by inhibiting autophagy via the PI3K/Akt/ mTOR signalling pathway. Biochem. J., 474, 2733-2747.

Ellinghaus, P., Perzborn, E., Hauenschild, P., Gerdes, C., Heitmeier, S., Visser, M., Summer, H. \& Laux, V. (2016) Expression of pro-inflammatory genes in human endothelial cells: comparison of rivaroxaban and dabigatran. Thromb. Res., 142, 44-51.

Goldberg, R.B. (2009) Cytokine and cytokine-like inflammation markers, endothelial dysfunction, and imbalanced coagulation in development of diabetes and its complications. J. Clin. Endocrinol. Metab., 94, 3171-3182.

Goto, S., Ogawa, H., Takeuchi, M., Flather, M.D. \& Bhatt, D.L.; the J-LANCELOT (Japanese-Lesson from Antagonizing the Cellular Effect of Thrombin) Investigators (2010) Doubleblind, placebo-controlled Phase II studies of the protease-activated receptor 1 antagonist E5555 (atopaxar) in Japanese patients with acute coronary syndrome or high-risk coronary artery disease. Eur. Heart J., 31, 2601-2613.

Gregg, E.W., Williams, D.E. \& Geiss, L. (2014) Changes in diabetes-related complications in the United States. N. Engl. J. Med., 371, 286-287.

Grover, S.P. \& Mackman, N. (2018) Tissue factor: an essential mediator of hemostasis and trigger of thrombosis. Arterioscler. Thromb. Vasc. Biol., 38, 709-725.

Han, Y., Tian, L., Ma, F., Tesch, G., Vesey, D.A., Gobe, G.C., Lohman, R.J., Morais, C., Suen, J.Y., Fairlie, D.P. \& NikolicPaterson, D.J. (2019) Pharmacological inhibition of proteaseactivated receptor-2 reduces crescent formation in rat nephrotoxic serum nephritis. Clin. Exp. Pharmacol. Physiol., 46, 456-464.

Hayashi, S., Oe, Y., Fushima, T., Sato, E., Sato, H., Ito, S. \& Takahashi, N. (2016) Protease-activated receptor 2 exacerbates adenine-induced renal tubulointerstitial injury in mice. Biochem. Biophys. Res. Commun.,483, 547-552.

Isermann, B. (2017) Homeostatic effects of coagulation proteasedependent signaling and protease activated receptors. $J$. Thromb. Haemost., 15, 1273-1284.

Jiang, Y., Yau, M.K., Lim, J., Wu, K.C., Xu, W., Suen, J.Y. \& Fairlie, D.P. (2018) A potent antagonist of protease-activated receptor 2 that inhibits multiple signaling functions in human cancer cells. J. Pharmacol. Exp. Ther, 364, 246-257.

Kainz, A., Hronsky, M., Stel, V.S., Jager, K.J., Geroldinger, A., Dunkler, D., Heinze, G., Tripepi, G. \& Oberbauer, R. (2015) Prediction of prevalence of chronic kidney disease in diabetic patients in countries of the European Union up to 2025. Nephrol. Dial. Transplant., 30 Suppl 4, iv113-118.

Kolachalama, V.B., Shashar, M., Alousi, F., Shivanna, S., Rijal, K., Belghasem, M.E., Walker, J., Matsuura, S., Chang, G.H., Gibson, C.M., Dember, L.M., Francis, J.M., Ravid, K. \& Chitalia, V.C. (2018) Uremic solute-aryl hydrocarbon receptor-tissue factor axis associates with thrombosis after vascular injury in humans. J. Am. Soc. Nephrol., 29, 10631072.

Li, F., Wang, C.H., Wang, J.G., Thai, T., Boysen, G., Xu, L., Turner, A.L., Wolberg, A.S., Mackman, N., Maeda, N. \& Takahashi, N. (2010) Elevated tissue factor expression contributes to exacerbated diabetic nephropathy in mice lacking eNOS fed a high fat diet. J. Thromb. Haemost., 8, 2122-2132.

Lim, J., Iyer, A., Liu, L., Suen, J.Y., Lohman, R.J., Seow, V., Yau, M.K., Brown, L. \& Fairlie, D.P. (2013) Diet-induced obesity, adipose inflammation, and metabolic dysfunction correlating with PAR2 expression are attenuated by PAR2 antagonism. FASEB J., 27, 4757-4767.

Liyanage, T., Ninomiya, T., Jha, V., Neal, B., Patrice, H.M., Okpechi, I., Zhao, M.H., Lv, J., Garg, A.X., Knight, J., Rodgers, A., Gallagher, M., Kotwal, S., Cass, A. \& Perkovic, V. (2015) Worldwide access to treatment for end-stage kidney disease: a systematic review. Lancet, 385, 1975-1982.

Lok, S.W.Y., Yiu, W.H., Li, H., Xue, R., Zou, Y., Li, B., Chan, K.W., Chan, L.Y.Y., Leung, J.C.K., Lai, K.N. \& Tang, S.C.W. (2020) The PAR-1 antagonist vorapaxar ameliorates kidney injury and tubulointerstitial fibrosis. Clin. Sci. (Lond.), 134, 2873-2891.

Lv, B., Wang, H., Tang, Y., Fan, Z., Xiao, X. \& Chen, F. (2009) High-mobility group box 1 protein induces tissue factor expression in vascular endothelial cells via activation of NF-kappaB and Egr-1. Thromb. Haemost., 102, 352-359.

Madhusudhan, T., Kerlin, B.A. \& Isermann, B. (2016) The emerging role of coagulation proteases in kidney disease. Nat. Rev. Nephrol., 12, 94-109.

Madhusudhan, T., Wang, H., Straub, B.K., Gröne, E., Zhou, Q., Shahzad, K., Müller-Krebs, S., Schwenger, V., Gerlitz, B., Grinnell, B.W., Griffin, J.H., Reiser, J., Gröne, H.J., Esmon, C.T., Nawroth, P.P., et al. (2012) Cytoprotective signaling by activated protein $\mathrm{C}$ requires protease-activated receptor-3 in podocytes. Blood, 119, 874-883.

Mitsui, S., Oe, Y., Sekimoto, A., Sato, E., Hashizume, Y., Yamakage, S., Kumakura, S., Sato, H., Ito, S. \& Takahashi, N. (2020) Dual blockade of protease-activated receptor 1 and 2 additively ameliorates diabetic kidney disease. Am. J. Physiol. Renal Physiol., 318, F1067-F1073.

Nakagawa, T., Sato, W., Glushakova, O., Heinig, M., Clarke, T., Campbell-Thompson, M., Yuzawa, Y., Atkinson, M.A., Johnson, R.J. \& Croker, B. (2007) Diabetic endothelial nitric oxide synthase knockout mice develop advanced diabetic nephropathy. J. Am. Soc. Nephrol., 18, 539-550.

Nakagawa, T., Tanabe, K., Croker, B.P., Johnson, R.J., Grant, M.B., Kosugi, T. \& Li, Q. (2011) Endothelial dysfunction as a potential contributor in diabetic nephropathy. Nat. Rev. Nephrol., 7, 36-44.

Nitta, K., Goto, S., Masakane, I., Hanafusa, N., Taniguchi, M., Hasegawa, T., Nakai, S., Wada, A., Hamano, T., Hoshino, J., Joki, N., Abe, M., Yamamoto, K. \& Nakamoto, H.; the Japanese Society for Dialysis Therapy Renal Data Registry Committee (2020) Annual dialysis data report for 2018, JSDT Renal Data Registry: survey methods, facility data, incidence, prevalence, and mortality. Ren. Replace. Ther, $\mathbf{6}, 41$.

Noiri, E., Satoh, H., Taguchi, J., Brodsky, S.V., Nakao, A., Ogawa, Y., Nishijima, S., Yokomizo, T., Tokunaga, K. \& Fujita, T. (2002) Association of eNOS Glu298Asp polymorphism with end-stage renal disease. Hypertension, 40, 535-540.

Nystedt, S., Ramakrishnan, V. \& Sundelin, J. (1996) The proteinase-activated receptor 2 is induced by inflammatory mediators in human endothelial cells. Comparison with the thrombin receptor. J. Biol. Chem., 271, 14910-14915.

Oe, Y., Fushima, T., Sato, E., Sekimoto, A., Kisu, K., Sato, H., Sugawara, J., Ito, S. \& Takahashi, N. (2019) Protease-activated receptor 2 protects against VEGF inhibitor-induced 
glomerular endothelial and podocyte injury. Sci. Rep., 9, 2986.

Oe, Y., Hayashi, S., Fushima, T., Sato, E., Kisu, K., Sato, H., Ito, S. \& Takahashi, N. (2016) Coagulation factor Xa and proteaseactivated receptor 2 as novel therapeutic targets for diabetic nephropathy. Arterioscler. Thromb. Vasc. Biol., 36, 15251533.

Ogurtsova, K., da Rocha Fernandes, J.D., Huang, Y., Linnenkamp, U., Guariguata, L., Cho, N.H., Cavan, D., Shaw, J.E. \& Makaroff, L.E. (2017) IDF Diabetes Atlas: Global estimates for the prevalence of diabetes for 2015 and 2040. Diabetes Res. Clin. Pract., 128, 40-50.

Østerud, B. \& Bjørklid, E. (2006) Sources of tissue factor. Semin. Thromb. Hemost., 32, 11-23.

Owens, A.P., Passam, F.H., Antoniak, S., Marshall, S.M., McDaniel, A.L., Rudel, L., Williams, J.C., Hubbard, B.K., Dutton, J.A., Wang, J., Tobias, P.S., Curtiss, L.K., Daugherty, A., Kirchhofer, D., Luyendyk, J.P., et al. (2012) Monocyte tissue factor-dependent activation of coagulation in hypercholesterolemic mice and monkeys is inhibited by simvastatin. $J$. Clin. Invest., 122, 558-568.

Pan, L., Ye, Y., Wo, M., Bao, D., Zhu, F., Cheng, M., Ni, X. \& Fei, $X$. (2018) Clinical significance of hemostatic parameters in the prediction for type 2 diabetes mellitus and diabetic nephropathy. Dis. Markers, 2018, 5214376.

Patel, M.R., Mahaffey, K.W., Garg, J., Pan, G., Singer, D.E., Hacke, W., Breithardt, G., Halperin, J.L., Hankey, G.J., Piccini, J.P., Becker, R.C., Nessel, C.C., Paolini, J.F., Berkowitz, S.D., Fox, K.A., et al. (2011) Rivaroxaban versus warfarin in nonvalvular atrial fibrillation. N. Engl. J. Med., 365, 883-891.

Pawlinski, R., Wang, J.G., Owens, A.P., Williams, J., Antoniak, S., Tencati, M., Luther, T., Rowley, J.W., Low, E.N., Weyrich, A.S. \& Mackman, N. (2010) Hematopoietic and nonhematopoietic cell tissue factor activates the coagulation cascade in endotoxemic mice. Blood, 116, 806-814.

Posma, J.J., Grover, S.P., Hisada, Y., Owens, A.P., Antoniak, S., Spronk, H.M. \& Mackman, N. (2019) Roles of coagulation proteases and PARs (Protease-Activated Receptors) in mouse models of inflammatory diseases. Arterioscler. Thromb. Vasc. Biol., 39, 13-24.

Robertson, L., Kesteven, P. \& McCaslin, J.E. (2015) Oral direct thrombin inhibitors or oral factor Xa inhibitors for the treatment of deep vein thrombosis. Cochrane Database Syst. Rev., CD010956.

Rogero, M.M. \& Calder, P.C. (2018) Obesity, inflammation, tolllike receptor 4 and fatty acids. Nutrients, 10, 432.

Rothmeier, A.S. \& Ruf, W. (2012) Protease-activated receptor 2 signaling in inflammation. Semin. Immunopathol., 34, 133-149.

Samad, F. \& Ruf, W. (2013) Inflammation, obesity, and thrombosis. Blood, 122, 3415-3422.

Shrestha, C., Ito, T., Kawahara, K., Shrestha, B., Yamakuchi, M., Hashiguchi, T. \& Maruyama, I. (2013) Saturated fatty acid palmitate induces extracellular release of histone H3: a possible mechanistic basis for high-fat diet-induced inflammation and thrombosis. Biochem. Biophys. Res. Commun., 437, 573-578.

Sörensen, I., Susnik, N., Inhester, T., Degen, J.L., Melk, A., Haller, H. \& Schmitt, R. (2011) Fibrinogen, acting as a mitogen for tubulointerstitial fibroblasts, promotes renal fibrosis. Kidney Int., 80, 1035-1044.

Sumi, A., Yamanaka-Hanada, N., Bai, F., Makino, T., Mizukami, H. \& Ono, T. (2011) Roles of coagulation pathway and factor Xa in the progression of diabetic nephropathy in $\mathrm{db} / \mathrm{db}$ mice. Biol. Pharm. Bull., 34, 824-830.
Tanaka, M., Arai, H., Liu, N., Nogaki, F., Nomura, K., Kasuno, K., Oida, E., Kita, T. \& Ono, T. (2005) Role of coagulation factor $\mathrm{Xa}$ and protease-activated receptor 2 in human mesangial cell proliferation. Kidney Int., 67, 2123-2133.

Tricoci, P., Huang, Z., Held, C., Moliterno, D.J., Armstrong, P.W., Van de Werf, F., White, H.D., Aylward, P.E., Wallentin, L., Chen, E., Lokhnygina, Y., Pei, J., Leonardi, S., Rorick, T.L., Kilian, A.M., et al. (2012) Thrombin-receptor antagonist vorapaxar in acute coronary syndromes. N. Engl. J. Med., 366, 20-33.

Vesey, D.A., Cheung, C.W., Kruger, W.A., Poronnik, P., Gobe, G. \& Johnson, D.W. (2005) Thrombin stimulates proinflammatory and proliferative responses in primary cultures of human proximal tubule cells. Kidney Int., 67, 1315-1329.

Vesey, D.A., Suen, J.Y., Seow, V., Lohman, R.J., Liu, L., Gobe, G.C., Johnson, D.W. \& Fairlie, D.P. (2013) PAR2-induced inflammatory responses in human kidney tubular epithelial cells. Am. J. Physiol. Renal Physiol., 304, F737-750.

Waasdorp, M., de Rooij, D.M., Florquin, S., Duitman, J. \& Spek, C.A. (2019) Protease-activated receptor-1 contributes to renal injury and interstitial fibrosis during chronic obstructive nephropathy. J. Cell. Mol. Med., 23, 1268-1279.

Waasdorp, M., Duitman, J., Florquin, S. \& Spek, C.A. (2016) Protease-activated receptor-1 deficiency protects against streptozotocin-induced diabetic nephropathy in mice. Sci. Rep., 6, 33030 .

Waasdorp, M., Duitman, J., Florquin, S., Spek, C.A. \& Spek, A.C. (2017) Protease activated receptor 2 in diabetic nephropathy: a double edged sword. Am. J. Transl. Res., 9, 4512-4520.

Walford, G. \& Loscalzo, J. (2003) Nitric oxide in vascular biology. J. Thromb. Haemost., 1, 2112-2118.

Wang, C.H., Li, F., Hiller, S., Kim, H.S., Maeda, N., Smithies, O. \& Takahashi, N. (2011a) A modest decrease in endothelial NOS in mice comparable to that associated with human NOS3 variants exacerbates diabetic nephropathy. Proc. Natl. Acad. Sci. U. S. A., 108, 2070-2075.

Wang, H., Madhusudhan, T., He, T., Hummel, B., Schmidt, S., Vinnikov, I.A., Shahzad, K., Kashif, M., Muller-Krebs, S., Schwenger, V., Bierhaus, A., Rudofsky, G., Nawroth, P.P. \& Isermann, B. (2011b) Low but sustained coagulation activation ameliorates glucose-induced podocyte apoptosis: protective effect of factor V Leiden in diabetic nephropathy. Blood, 117, 5231-5242.

Watanabe, M., Oe, Y., Sato, E., Sekimoto, A., Sato, H., Ito, S. \& Takahashi, N. (2019) Protease-activated receptor 2 exacerbates cisplatin-induced nephrotoxicity. Am. J. Physiol. Renal Physiol., 316, F654-F659.

Witkowski, M., Landmesser, U. \& Rauch, U. (2016) Tissue factor as a link between inflammation and coagulation. Trends Cardiovasc. Med., 26, 297-303.

Zhang, J., Wang, Y., Zhang, R., Li, H., Han, Q., Wu, Y., Wang, S., Guo, R., Wang, T., Li, L. \& Liu, F. (2018) Serum fibrinogen predicts diabetic ESRD in patients with type 2 diabetes mellitus. Diabetes Res. Clin. Pract., 141, 1-9.

Zhang, Y., Xiao, H.Q., Zeng, X.T., Zuo, H.X. \& Xu, Y.C. (2015) Associations between endothelial nitric oxide synthase polymorphisms and risk of diabetic nephropathy: an updated metaanalysis. Ren. Fail., 37, 312-326.

Zhao, H.J., Wang, S., Cheng, H., Zhang, M.Z., Takahashi, T., Fogo, A.B., Breyer, M.D. \& Harris, R.C. (2006) Endothelial nitric oxide synthase deficiency produces accelerated nephropathy in diabetic mice. J. Am. Soc. Nephrol., 17, 2664-2669.

Zhao, P., Metcalf, M. \& Bunnett, N.W. (2014) Biased signaling of protease-activated receptors. Front. Endocrinol. (Lausanne), $5,67$. 